\title{
PROCESSO DE ENVELHECIMENTO E SUA RELAÇÃO COM A MORTE: percepção do idoso hospitalizado em unidade de cuidados semi-intensivos
}

\author{
Gabriela Rodrigues Zinn' \\ Beatriz Aparecida Ozello Gutierrez²
}

\section{Resumo}

O objetivo deste estudo é compreender o processo de envelhecimento humano e sua relação com a morte sob a percepção do idoso hospitalizado em unidade de cuidados semi-intensivos. Realizou-se uma pesquisa qualitativa segundo a análise de discurso temática. Desvelaram-se aspectos positivos e negativos nesse campo de investigação, de acordo com a história pessoal, crenças e valores de cada idoso. Destaca-se a importância de valorizar as experiências de vida dessa população.

Palavras-chave: Envelhecimento. Morte. Idoso.

\section{Introdução}

O envelhecer e o morrer são fenômenos inerentes à vida em todas as suas formas; porém, as interpretações e os sentimentos que envolvem tais temas variam de um ser humano para outro.

Dentre as muitas definições de envelhecimento, temos que este é

[... ] um processo seqüencial, individual, acumulativo, irreversível, universal, não-patológico, de deterioração de um organismo maduro, próprio a todos os membros de uma espécie, de maneira que o tempo o torne menos capaz de fazer frente ao estresse do meio ambiente e, portanto, aumente sua possibilidade de morte (ORGANIZACIÓN PANAMERICANA DE LA SALUD, 2003, p. 30).

1 Enfermeira Especialista em Enfermagem Gerontológica e Mestre em Psicologia da Educação. Docente do Curso de Enfermagem da Universidade Paulista. E-mail: gabriela.zinn@gmail.com

2 Enfermeira Doutora em Enfermagem pela Escola de Enfermagem da Universidade de São Paulo (USP). Docente do Curso de Gerontologia da Escola de Artes, Ciências e Humanidades da USP. E-mail: biagutierrez@ yahoo.com.br

Estud. interdiscip. envelhec., Porto Alegre, v. 13, n. 1, p. 79-93, 2008. 
Ressalta-se nesta definição a relação entre o envelhecimento e a morte, na qual o envelhecer é descrito de forma a lembrar um caminhar para o fim da vida.

Ao contrário da afirmativa anterior, a morte pode ser compreendida não como um ponto final na existência, e sim como um elemento constitutivo dela. Assim, “O morrer sempre será considerado um desafio a ser vencido e não um momento da existência humana, que vivido com autenticidade, é a expressão máxima da liberdade do ser.” (BOEMER, 1985, p. 58). O envelhecimento e a morte são fenômenos que envolvem sentimentos variados e que são contextualizados conforme os múltiplos aspectos da vida humana.

O número de idosos no Brasil e no mundo é cada vez mais significativo como descrevem várias pesquisas; somando-se a esse fato, a área de saúde vem se preocupando progressivamente com essa faixa etária, em busca de um caminho para promover a saúde dos idosos da forma mais adequada (CAMACHO, 2002; FREITAS et al., 2002).

Dessa forma, acreditamos que a compreensão acerca da finitude na perspectiva do idoso, o qual vive o processo de envelhecimento e está na iminência da morte, é um passo importante para fomentar a reflexão, buscando uma forma positiva de lidar com tais questões: envelhecimento e morte.

Considerando que a enfermagem tem como filosofia assistir o paciente holisticamente, uma vez que este cuidar abrange as necessidades relacionadas aos aspectos físicos, emocionais, sociais e espirituais; esse trabalho busca a reflexão sobre as percepções dos pacientes idosos acerca do seu processo de envelhecimento e sua relação com a morte na tentativa de propiciar a melhor qualidade de assistência.

Diante do exposto, os resultados do presente estudo poderão subsidiar novas formas de abordagem ao idoso, considerando o aspecto empático, de se colocar no lugar, de olhar por meio do olhar do outro em busca da valorização do ser humano, no caso, do ser idoso.

Destaca-se que a empatia acontece quando a pessoa que assume o comportamento empático percebe os sentimentos da outra pessoa e relaciona esses sentimentos com a perspectiva e o contexto desta, comunicando a seguir a sua compreensão (EGAN, 1994).

O presente estudo tem como objetivo compreender o processo de envelhecimento humano e sua relação com a morte, sob a percepção do idoso hospitalizado em unidade de cuidados semi-intensivos.

Refletindo sobre os temas envelhecimento e morte e, relacionando-os com a vivência de idosos hospitalizados em unidade de tratamento semi- 
intensivo, que poderiam estar mais próximos desta reflexão, decidimos pela realização do presente estudo.

\section{Método}

Trata-se de um estudo descritivo-exploratório de cunho qualitativo. Como referencial teórico para os procedimentos de coleta e análise dos dados, utilizamos o trabalho de Minayo (1999), que discute a pesquisa qualitativa em saúde.

Após a aprovação do projeto pelo Comitê de Ética e pelo Comitê de Pesquisa da instituição envolvida no estudo, a pesquisadora abordou idosos hospitalizados, esclarecendo-os sobre os objetivos do estudo, a voluntariedade de participação e a garantia do anonimato, verbalmente e em forma de documento. Após os esclarecimentos, verificou-se o interesse dos sujeitos em participar, e os que concordaram assinaram o Termo de Consentimento Livre e Esclarecido, iniciando-se, dessa forma, a coleta de dados.

Fizeram parte desta pesquisa seis pacientes idosos internados na unidade semi-intensiva de um hospital universitário de São Paulo que, após os devidos esclarecimentos, concordaram em participar de forma livre e que, para isso, possuíam sua capacidade cognitiva preservada. Foram consideradas as disponibilidades dos sujeitos em participarem do estudo e o período de tempo disponível para a realização das entrevistas.

O número da amostra não foi pré-determinado conforme preconizado pelo referencial metodológico.

A caracterização dos entrevistados que participaram da pesquisa foi a seguinte: a média de idade foi de 78,7 anos, sendo o mais jovem com 66 anos e o mais velho com 91 anos; 50\% eram do sexo masculino, e 50\% do sexo feminino; $50 \%$ apresentavam o ensino fundamental incompleto, sendo o ensino médio completo o maior nível de escolaridade; $50 \%$ eram pacientes cirúrgicos, e 50\% eram pacientes clínicos, sendo 50\% da população internada devido a eventos agudos, e 50\% correspondiam a eventos crônicos; $66,6 \%$ dos entrevistados eram católicos, $16,7 \%$ espíritas e os outros $16,7 \%$ verbalizaram a crença em religiões distintas.

Os discursos foram obtidos por meio de entrevistas individuais gravadas em fita cassete mediante o consentimento dos sujeitos.

A questão norteadora da entrevista foi: Considerando as fases do ciclo da vida (infância, adolescência, fase adulta e velhice); como o(a) senhor(a) vivencia o processo de envelhecimento? 
As entrevistas foram transcritas na íntegra e os discursos foram submetidos à análise de conteúdo e, portanto, recortados e compilados a partir das unidades de significado (categorias e subcategorias) segundo Minayo (1999).

\section{Resultados}

Para a realização da análise dos dados obtidos, partimos da premissa de que os idosos compartilham a experiência de estarem vivenciando o processo de envelhecimento e a finitude. A partir de tal constatação, realizamos os recortes temáticos nas narrativas, visando à análise crítica, e então foram desveladas as categorias e subcategorias descritas a seguir.

\subsection{O Processo de Envelhecimento}

Os idosos convivem com crenças sociais e estereótipos que supervalorizam os pontos negativos da velhice, tais como: perdas fisiológicas, incapacidades funcionais, restrições, déficit cognitivo, entre outros, muitas vezes, essa atmosfera negativista sobrepõe o lado positivo da velhice, marcado pela fase constituída por ganhos e experiências compensatórias.

3.1.1 Colhendo os Frutos: conseqüência de valores e atitudes

Inserido nesta temática, encontramos os idosos percebendo o envelhecer como um fenômeno resultante das atitudes e valores cultivados durante a vida, colocados por parte dos sujeitos do presente estudo sob uma perspectiva positiva.

Eu nunca fiz mal a ninguém, nunca maltratei ninguém. Eu sou muito feliz! É isso, foi assim a minha vida!

Servir o máximo, mas não como obrigação. Não beber, não ultrapassar as noites, e estar de bem com todo mundo... $\mathrm{O}$ envelhecimento é conseqüência da sua vida mesmo, depende do seu comportamento.

O amor é a base principal da gente! É uma fase boa, porque eu trabalhei muito... Agora estou sossegada. Eu me sinto sossegada. Está tudo bem. 
É relevante considerar as inovações no curso da vida, pois esse reconhecimento pode direcionar as pessoas por novos padrões de comportamento na maturidade e na velhice, e ainda propiciar a elaboração de políticas públicas condizentes com as mudanças sociais e culturais da sociedade (GIELE, 1998).

\subsubsection{Envelhecimento Feliz}

Esta subcategoria referencia a alegria de ser idoso. Uma forma otimista e positiva de vivenciar o processo de envelhecimento.

Eu tenho alegria do envelhecimento. Para mim é a fase melhor que eu estou passando, sabe? Faço academia de ginástica, danço forró na academia... Eu tenho alegria de viver, tenho muita alegria e quero dar alegria para as pessoas.

Destaca-se a percepção de que os relatos positivos em relação ao envelhecimento emergiram de idosos que verbalizaram o passado de forma tranqüila, ou relatando uma vida feliz ou com dificuldades superadas. Reforçando o tema analisado anteriormente que revela o processo de envelhecimento como conseqüência do processo da vida, temos que: vida feliz $=$ envelhecimento feliz.

\subsubsection{Valorizando a Sabedoria}

A sabedoria adquirida pela experiência de vida é valorizada pelos idosos, alguns verbalizaram diretamente esta afirmativa, mas a maioria demonstra isto nas entrelinhas, mostrando-se orgulhosos em contar passagens da vida, interessando-se por poder colaborar com a pesquisa e, muitas vezes, aconselhando a pesquisadora.

A verdade do conhecimento não pode ter outra fonte se não a confrontação sistemática da lógica e da experiência, você com conhecimento você fala com lógica, fala com experiência, e outra coisa também, porque a nobreza é definida pelas ações de cada um... 
O idoso é uma fonte de experiência e de um saber único e exclusivo decorrente dos anos vividos, por isso deve ser respeitado diante dos mais jovens e ainda pelos que estão na mesma fase da vida (DEBERT, 2004).

\subsubsection{Valorização do Trabalho}

O trabalho é colocado como o combustível para a vida.

Vivo, ué, tem que acontecer essa fase com a gente, que a minha luta é bastante, trabalhando, né! Eu trabalho ainda. Eu tenho sítio, né? Nunca pára.

As pessoas atribuem um significado positivo ao trabalho, tanto na dimensão econômica quanto na dimensão existencial (BRÊTAS; OLIVEIRA, 2000).

\subsubsection{A Desvalorização do Velho pelo Novo}

A tristeza expressa de forma não-verbal ao relatar o desrespeito que o idoso sofre decorrente das atitudes dos mais jovens é marcante. Esclarecendo que a comunicação não-verbal é aquela que não se associa às palavras, por exemplo, os gestos, o silêncio, as expressões faciais, a postura corporal, dentre outros (SILVA, 1996).

Só que agora é bem diferente. Parece que os mais jovem não querem saber dos mais velhos. Eles não querem respeitar os mais velhos, eles acham que nunca vão ficar assim. Então, eu acho que desprezam. Posso até estar enganada, mas a gente tem essa impressão: que desprezam... Mas o que eu acho é que parece que maltratam muito os mais velhos, não querem saber do que eles falam...

Pensando assim, o lidar com atitudes e significados frente ao velho e à velhice é uma questão educacional. Ou seja, resolver a então chamada questão social da velhice ou eventuais frustrações geradas pelo envelhecimento em nível individual, passa por providências de natureza educacional. Não no sentido de ensinar as pessoas a envelhecerem ou de preparar para a velhice, ou mesmo de lidar não preconceituosamente com os velhos e a velhice. O que importa realmente é ensinar as pessoas a construírem uma 
realidade social e individual na qual essas questões tenham chance mínima de existência (NERI, 1991).

\subsubsection{Medo do Abandono}

O medo do confinamento está associado à desvalorização do idoso.

Parece que só querem que vai para asilo e acaba, não sei. Qualquer coisa, asilo.

A palavra asilo é carregada de estereótipos negativos. Preparar os idosos para um envelhecimento adequado é dar-lhes espaço para o desenvolvimento de uma intimidade plena, um espaço doméstico perdido que poderia ser recuperado (DEBERT, 2004).

\subsubsection{Momento de Reflexão do Paciente e Família}

Nesta temática, encontramos algo específico do idoso hospitalizado, quando o processo de envelhecimento sofre a ação de alguma enfermidade, e neste momento pode ocorrer a mobilização da família.

E quando eu internei aqui ela ficou comigo no pronto socorro, meu Deus! Parece até que eu pude conversar com ela e ainda ela veio!

Destaca-se aqui, infelizmente, a obrigatoriedade de um acompanhante neste momento da internação devido a normas da instituição, tornando questionável a disponibilização real desta filha em permanecer com a mãe.

Agora você precisa ver que beleza que é minhas filhas vieram aqui, cada uma segurando em uma mão e falava: pai eu estou contente de te ver assim bem, o senhor é minha vida pai, o senhor é minha vida.

As relações familiares são importantes na assistência ao idoso e nas expectativas em relação ao processo de envelhecimento (NERI, 1991). 


\subsubsection{Envelhecimento Sinônimo de Sofrimento}

Aqui se constata o relato negativo acerca do envelhecimento.

Nessa idade é melhor, mais bom é Deus tirar logo, porque é melhor do que ficar penando, do que ficar sofrendo... Essas pernas doentes, eu desse jeito.

No momento em que doença e morte são citadas, é unânime a opção de que a morte é preferível à invalidez, que sugere a perda de autonomia e a vida vegetativa (DEBERT, 2004).

\subsection{A Morte}

O surgimento de uma doença grave, sem possibilidades de cura, consiste em uma situação problemática que mobiliza um complexo psico-sócioespiritual para enfrentá-la, pois esse processo desencadeia uma mobilização tanto no enfermo como na sua família e/ou em outras pessoas com quem o doente mantém relacionamentos.

Outro aspecto que se torna presente na vida dessas pessoas é a iminência da morte, que provoca nos indivíduos reações diferentes diante do processo de adoecer. Alguns se retraem e vivenciam o medo, outros, porém, começam a valorizar o tempo de que ainda dispõem e passam a enxergar a vida de maneira mais plena e adaptada. No entanto, a visão relacionada ao ato de morrer tem se modificado com o decorrer do processo de transformação das sociedades, e está diretamente ligado ao estágio de desenvolvimento dessa sociedade, assim como as suas especificidades, valores e ritos.

\subsubsection{Desejo pela Boa Morte}

A maioria das pessoas almeja a boa morte.

Ah, eu penso que Deus me dê uma morte boa, uma boa morte, me colocar num bom lugar, né? A morte de repente, né! Me dá uma morte como a do meu pai, durmo e não acordo mais.

O termo "boa morte" é definido como sendo a morte sem dor nem sofrimento, que respeita os desejos do paciente e seus familiares, e segue os 
princípios clínicos, culturais e éticos que permeiam a sociedade em questão. Contudo, é necessário um planejamento ideal para a assistência no fim da vida, que inclua um tratamento favorável para o paciente, seus familiares e a equipe de saúde que presta cuidados (INSTITUTE OF MEDICINE, 1997).

\subsubsection{A Vida Continua}

A crença na vida após a morte leva a um enfrentamento mais tranqüilo diante da possibilidade de morte.

Agora, que tem vida após a morte, tem. A morte para mim não existe, não existe morte pra mim. Eu estudei espiritismo, estudei esoterismo, budismo, todas essas religiões ensinam que não existe morte. Então tem gente que pergunta assim: "você tem medo de morrer?”. Eu digo: “eu não tenho medo de morrer", porque pra mim é um novo nascimento, sabe? A morte. Renascer de novo.

Ao falar a respeito da morte sob o aspecto espiritual, temos que ela é uma porta de transição que leva de uma forma de vida a outra, pois a vida é contínua e eterna. A maioria das religiões e escolas espiritualistas prega o conceito de imortalidade e indestrutibilidade da alma humana (GIMENEZ, 2003).

\subsubsection{Sofrimento após Perda de Ente Querido}

A morte é lembrada como sofrimento, mas quando relacionada a pessoas queridas.

Já que aqueles dois que falei morreram um de acidente e o outro foi morto. Sofri muito!

Aí depois que mataram a minha filha, e a neta, que passou um caminhão de peixe em cima da Brasília, aí eu relaxei um pouco, mas não assim espiritualmente, eu relaxei das coisas, já não queria saber de mais nada.

Cabe destacar que, em relação à morte, cada sociedade tem seus próprios comportamentos, hábitos, crenças e atitudes, que oferecem aos indi- 
víduos uma orientação de como devem comportar-se e o que devem ou não fazer, refletindo a cultura própria de cada região e, também, diferenciando-a de outras (GUTIERREZ, 2003).

\subsubsection{Negando a Morte}

É necessário refletir a respeito do quanto esclarecemos o paciente que assistimos e seus responsáveis, para que eles possam optar pela terapêutica com efetiva liberdade e autonomia. O trecho a seguir contrapõe essa postura:

Ah, a gente nunca pensa que vai assim... logo, mas um dia vai, né? Todo mundo vai, né? A gente, assim, não pode pensar que vai morrer, né? Não pode, se não você acaba entregando a vida mais de pressa. Eu falei para o médico antes de ontem, se o meu coração estava muito ruim; ele falou que não estava tão ruim assim; eu falei que então ainda dá para viver bastante, né? Ele falou talvez sim, talvez não [risos].

O princípio da autonomia refere-se à capacidade de a pessoa escolher, avaliar, isenta de pressões internas ou externas. É a capacidade de tomar conhecimento dos procedimentos a que será submetida, de seus benefícios e de seus possíveis riscos, para só então, livre de qualquer coação, expressar sua concordância com o tratamento. As pessoas que têm sua autonomia diminuída devem ser protegidas, uma vez que não são capazes de expressar seu consentimento (BRAUNER, 1999).

O conceito de liberdade do ser humano é denso porque se refere a uma realidade complexa na vida real. A liberdade humana tem concretamente bordas e limites e não se exime paradoxalmente de obrigações. Muitas ambigüidades socioculturais constrangem a liberdade e a liberdade humana passa a ser um ponto futuro, uma vocação, que passa necessariamente por um processo de libertação (ANJOS, 2003).

\subsubsection{Morte como Alívio do Sofrimento}

Verifica-se uma forma tranqüila de enfrentamento da morte, porém decorrente de uma situação de sofrimento, em que a morte aparece como a melhor opção. 
Para que ficar penando? Nessa idade é melhor, mais bom é Deus tirar logo, porque é melhor de que ficar penando, ficar sofrendo. Eu desse jeito! Sofrendo, com essas pernas doentes, sem conseguir andar direito, inchada... Eu prefiro morrer!

Parece que eu estou aqui há muito tempo, porque Deus não me manda já para o outro lado?

Nesta abordagem, o momento da morte é difícil, no entanto, mais penoso e mais árduo é o processo do morrer (HOFFMANN, 1993).

\subsubsection{Amparo na Religiosidade}

A espiritualidade é uma dimensão da personalidade que habita e se desenvolve no mais íntimo do ser, identifica-se com o si mesmo, que se integra com os valores culturais em um sistema de crenças, símbolos, visão de mundo e sentido de vida pessoal. E essa dimensão espiritual expressase em idéias, sentimentos, atitudes e condutas (RAMELLA; VARELLA, 2002). Tais significados aprecem no discurso abaixo:

Eu acho que quando é uma coisa que é por Deus, é uma coisa que é por Deus que eles falam; chegou a hora, chegou.

A morte é uma coisa que não se morre, mas é o corpo que morre, não o espírito. Tu vai e volta, se você cumprir a missão certa, não volta, fica em um outro planeta. Estou falando isso agora como espírita, tá! E se não cumpriu sua missão, outra vez volta aqui. Cumpriu sua missão vai para outro planeta. É, não tem jeito. Agora tem muitos que morrem antes porque... Deus é muito grande e sabe muitas coisas que nós não sabemos. Aí vê que esse cara não é bom, essa pessoa não serve, logo, logo Ele vai reencarnar essa pessoa outra vez e outra vez.

Cada pessoa tem sua maneira individual de enfrentar a morte. Aqueles pacientes que acreditam na vida depois da morte são menos ansiosos. Pessoas envolvidas em práticas religiosas ou espirituais são fisicamente mais saudáveis, possuem estilo de vida mais equilibrado e usam menos serviços de saúde (KOENIG, 2001). 


\section{Considerações Finais}

No contexto desta pesquisa, mergulhou-se na perspectiva do idoso hospitalizado e no que ele pensa sobre o processo de envelhecimento e sua relação com a morte, tendo como objetivo final possibilitar uma assistência de enfermagem mais efetiva e de qualidade.

Neste sentido, percebemos que, ao entrarmos em contato com o que o paciente/cliente acredita e espera, podemos assistir de forma mais eficaz, encontrando um ponto de equilíbrio entre o que se espera e o que é possível realizar, sempre discutindo e esclarecendo as possibilidades.

Pensando na prática da enfermagem, cada vez mais vem ao nosso encontro a importância de valorizar a história de vida do idoso e, ainda, não infantilizar ou realizar pré-julgamentos. Destaca-se que as pessoas idosas têm uma grande bagagem de aprendizado que não está relacionada com o grau de escolaridade, mas sim com a experiência de vida.

Identificar quando o idoso está vivenciando o processo de envelhecimento de forma tranqüila, resignada, com medo ou tristeza; e reconhecer os motivos que levam a tais posicionamentos diante do fenômeno envelhecimento são uma forma de humanizar a assistência. A intenção e a atenção direcionadas a esta descoberta já valorizam o idoso e tornam-se, por si, um ato terapêutico. O mesmo se aplica em relação à forma na qual o idoso enfrenta o fenômeno morte. Isto é humanizar em seu sentido real: respeitar a individualidade e a autonomia do idoso no dia-a-dia de nossa prática profissional.

\section{PROCESS OF HUMAN AGING AND ITS RELATION WITH DEATH: the perception of the aged hospitalized in unit of half- intensive cares}

\section{Abstract}

This study aims at understanding the human aging process and its relation with death in the perception of aged people hospitalized in half-intensive care units. It was a qualitative research based on the thematic analysis of speech. It showed positive and negative aspects in this field of inquiry in accordance with the personal history, beliefs, and values of each elderly. It detaches the importance to value the life experiences of this population. Keywords: Aging. Death. Aged. 


\section{REFERÊNCIAS}

ANJOS, Marcio Fabri. Rumos da Liberdade em Bioética: uma leitura teológica. O Mundo da Saúde, São Paulo, v. 27, n. 3, p. 473-478, 2003.

BOEMER, Magali. A Morte, o Morrer e o Morrendo: estudo de pacientes em fase terminal. 1985. 205 f. Tese (Doutorado) - Escola de Enfermagem de Ribeirão Preto, Universidade de São Paulo, São Paulo, 1985.

BRAUNER, Maria Claudia. A Bioética e os Progressos Tecnológicos da Medicina Moderna: quais os limites de segurança? São Leopoldo: Unisinos, 1999.

BRÊTAS, Ana Cristina Passarella; OLIVEIRA, Eleonora Menicucci de. Envelhecimento, Saúde e Trabalho: um estudo com aposentados e aposentadas. Acta Paulista de Enfermagem, São Paulo, v. 13, n. 1, p. 66-79, 2000.

CAMACHO, Alessandra Conceição Leite Funchal. A Gerontologia e a Interdisciplinaridade: aspectos para a enfermagem. Revista Latino-Americana de Enfermagem, Ribeirão Preto, v. 10, n. 2, p. 229-233, 2002.

DEBERT, Guita Grin. A Construção e a Reconstrução da Velhice: família, classe social e etnicidade. In: NERI, Anita Liberalesso; DEBERT, Guita Grin (Org.). Velhice e Sociedade. Campinas: Papirus, 2004. p. 41-68.

EGAN, Gerard. The Skilled Helper: a problem management approach to helping. 5th ed. Pacific Grove: Brooks: Cole, 1994.

FREITAS, Maria Célia et al. Perspectivas das Pesquisas em Gerontologia e Geriatria: revisão da literatura. Revista Latino-Americana de Enfermagem, Ribeirão Preto, v. 10, n. 2 p. 221-228, 2002.

GIELE, Jant Zollinger. Inovation in the Typical Life Course. In: GIELE, Jant Zollinger; ELDER, Glen Jr. (Ed.). Methods of Life Course Research: qualitative and quantitative approaches. Thousand Oaks: Sage Publications, 1998. p. 65-87. 
GIMENEZ, Maria da Glória Gonçalves. A Passagem entre a Vida e a Morte: uma perspectiva psico-espiritual em cuidados paliativos domiciliares. O Mundo da Saúde, São Paulo, v. 27, n. 1, p. 153-158, jan./mar. 2003.

GUTIERREZ, Beatriz Aparecida Ozello. O Processo de Morrer no Cotidiano do Trabalho dos Profissionais de Enfermagem de Unidade de Terapia Intensiva. 2003. $228 \mathrm{f}$. Tese (Doutorado) - Escola de Enfermagem, Universidade de São Paulo, São Paulo, 2003.

HOFFMANN, Leonel. A Morte na Infância e sua Representação para o Médico: reflexões sobre a prática pediátrica em diferentes contextos. Cadernos de Saúde Pública, Rio de Janeiro, v. 9, n. 3, p. 364-374, 1993.

INSTITUTE OF MEDICINE. Committee on Care at the End of Life. Approaching death: improving care at the end of life. Washington, DC: National Academy Press, 1997.

KOENIG, Harold G. Religion, spirituality, and medicine: how are they related and what does it mean? Mayo Clinic Proceedings, Durham, v. 76, n. 12, p. 1189-1191, 2001.

MINAYO, Maria Cecília de Souza. O Desafio do Conhecimento: pesquisa qualitativa em saúde. São Paulo: Hucitec, 1999.

NERI, Anita Liberalesso. Envelhecer num País de Jovens: significados de velho e velhice segundo brasileiros não idosos. Campinas: Unicamp, 1991.

ORGANIZACIÓN PANAMERICANA DE LA SALUD. Guia Clínica para Atención Primaria a las Personas Mayores. 3. ed. Washington, DC, 2003.

RAMELLA, G. G.; VARELLA, D. Espiritualidad y Autotrascendencia: explorando esta dimensión de la personalidad con el TCI de C. R. Cloningier. Psiquiatria.com, Palmanova, v. 6, n. 2, 2002. Disponible en: <http://www. psiquiatria.com/articulos/transtornos_de_la_personalidad/8322/>. Acesso en: 20 set. 2002.

SILVA, Maria Júlia Paes. Comunicação Tem Remédio. São Paulo: Gente, 1996. 
Recebido em: 02-10-2007

$1^{a}$ revisão: $25-03-2008$

$2^{a}$ revisão: $17-08-2008$

Aceite final: 22-08-2008

Estud. interdiscip. envelhec., Porto Alegre, v. 13, n. 1, p. 79-93, 2008. 